\title{
The history of ergot of rye (Claviceps purpurea) II: 1900-1940
}

\author{
MR Lee \\ Emeritus Professor of Clinical Pharmacology and Therapeutics, University of Edinburgh, Edinburgh, UK
}

ABSTRACT Ergot, in 1900, was a 'chemical mess'. Henry Wellcome, the pharmaceutical manufacturer, invited Henry Hallett Dale, a physiologist, to join his research department and solve this problem. Dale, in turn, recruited an outstanding group of scientists, including George Barger, Arthur Ewins and Harold Dudley, who would make distinguished contributions not only to the chemistry of ergot but also to the identification of acetylcholine, histamine and tyramine and to studies on their physiological effects. Initially Barger and Dale isolated the compound ergotoxine, but this proved to be a false lead; it was later shown to be a mixture of three different ergot alkaloids. The major success of the Wellcome group was the discovery and isolation of ergometrine, which would prove to be life-saving in postpartum haemorrhage. In 1917 Arthur Stoll and his colleagues started work on ergot at Sandoz Pharmaceuticals in Basel. A series of important results emerged over the next 30 years, including the isolation of ergotamine in 1918, an effective treatment for migraine with aura.
Published online December 2009

Correspondence to MR Lee, I 2 Polwarth Terrace, Edinburgh EHII INN

tel. $+44(0)$ I3I 3377386

KEYWORDS Henry Dale, ergometrine, ergotamine, ergotoxine, migraine, postpartum haemorrhage

DECLARATION OF INTERESTS No conflict of interests declared.

In 1904, at the age of 29, Henry Hallett Dale joined the Burroughs Wellcome Research Laboratory in London (Figure I). At one of their first meetings, its owner, Henry Wellcome, suggested that Dale should make an attempt to clear up the problem of ergot. The apprentice pharmacologist was less than keen to do so. He had previously described this area of research as the "morass of ergot'.' In 1904 nobody realised what a formidable chemical and biological problem ergot would prove to be. Indeed, Dale would write, some 30 years later, that had he realised that he was about to open the Pandora's box of pharmacology he might never have started on such a risky enterprise.'

Both good luck and judgement would favour Dale in this task. His fine judgement was shown in the first instance when he recruited George Barger, a brilliant young chemist who would help him in the extraction and analysis of samples of ergot from different sources. ${ }^{2,3}$ (For a detailed exposition of this ten-year co-operation the reader is referred to Barger's excellent monograph. ${ }^{4}$ ) Dale postulated that the vasodilator substance present in ergot was acetylcholine; with Arthur Ewins's help, this was later confirmed. Subsequently, Dale shared the Nobel Prize in Physiology with Otto Loewi for their work on this important cholinergic neurotransmitter. Barger eventually became Professor of Medicinal Chemistry at Edinburgh, where he carried out another important piece of research in collaboration with Charles Harington, isolating and later synthesising thyroxine for the first time. ${ }^{5}$

Luck played an important part in the Wellcome group's early experiments. Dale had received specimens of cat

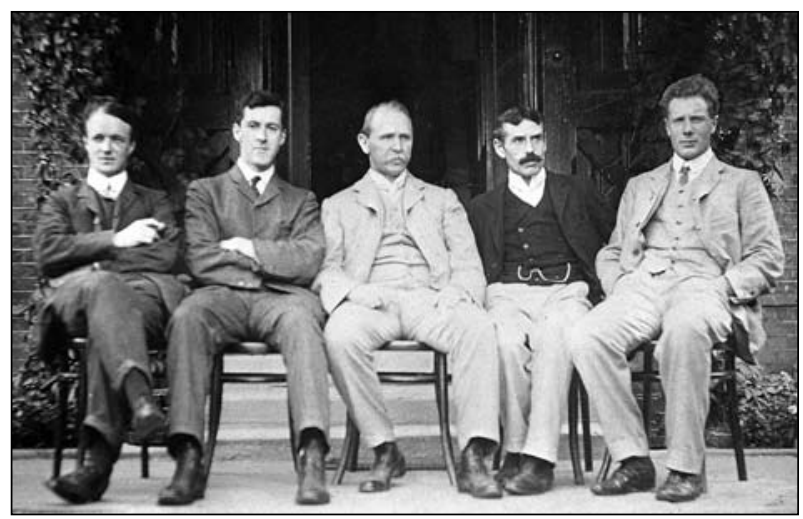

FIGURE I Scientific staff of the Wellcome Physiological Laboratories (1906). From left: CT Symons, HH Dale,

W Dowson, HJ Sudmerson and G Barger. (With kind permission of the Wellcome Library, London.)

adrenal gland and it was his task to assay them for the content of adrenaline, the newly discovered pressor catecholamine. Dale found, to his surprise, that if the cat had been pretreated with one of Barger's ergot preparations, no pressor response could be obtained. Sometimes the blood pressure would not rise but fall. He and Barger concluded that the ergot preparation was capable of reversing the action of adrenaline on the peripheral arterioles; that is, it blocked the effect. ${ }^{3}$ Dale suggested as a result of this series of experiments that receptors for adrenaline existed on the arterioles, which he called adrenoceptors. They could be activated by adrenaline and other pressor amines such as tyramine and ephedrine.

Barger then embarked on a ten-year exploration of ergot and made many different extracts with diverse 
solvents. Initially, he was baffled by the finding that sometimes an extract would raise the blood pressure, but the same preparation of the fungus extracted with a different solvent would lower the blood pressure. It was established later that in any given extract there could be ergotamine and ergometrine (pressor), acetylcholine (depressor), histamine (largely depressor) and tyramine (pressor). Moreover, if the ergot was not fresh and became contaminated with bacteria, the vasodepressor amines putrescine and cadaverine could be generated, which were also capable of lowering blood pressure. Thus ergot's net effect on blood pressure could be pressor, depressor or neutral.

As became apparent over time, Dale and Barger were a brilliant team. The former was an intuitive investigator and the latter a careful, painstaking analyst. Writing Dale's obituary, William Feldberg would say of him (using the same words that Hermann von Helmholtz had employed about the great physicist Michael Faraday) that 'the Boss smelled out the Truth'.

\section{ERGOTOXINE: A FALSE DAWN}

Dale and Barger, however, did make one mistake with regard to ergot which would complicate and delay the identification of pure ergot alkaloids. They isolated a crystalline solid from the mother liquor of ergot and assumed it to be a pure alkaloid. They called it ergotoxine and used it extensively in their experiments, ${ }^{4}$ but this product of crystallisation proved to be a false lead. We know now that closely related compounds can crystallise together. In 1943, Arthur Stoll and Albert Hofmann at Sandoz Pharmaceuticals in Basel, Switzerland, demonstrated that 'ergotoxine' was not a pure compound but a mixture in variable proportions of three closely related ergot alkaloids: ergocornine, ergocristine and ergocriptine. ${ }^{6}$ As a result of the variable composition of ergotoxine, the mixture of three alkaloids could and did show a lack of reproducibility in different bioassay preparations. ${ }^{6}$ This was a serious disappointment to Barger, Dale, Carr and Ewins after all their success with acetylcholine, histamine and tyramine.

\section{ERGOTAMINE}

In 19/7, Sandoz decided to enter the field of pharmacological research and appointed Stoll as director. A Swiss national by birth, he had been working with Richard Wilstätter in Munich on the isolation and identification of chlorophyll. Sandoz had plentiful supplies of dried ergot powder, and Stoll chose to work on the ergot alkaloids. Within 12 months, in a series of incisive experiments, he isolated and partially characterised the structure of the alkaloid ergotamine (Figure 2A). ${ }^{7}$ Many years later, in 195I, Stoll and his colleagues established its full structure and Hofmann (with co-workers) completed the synthesis in 1961.8 Once ergotamine

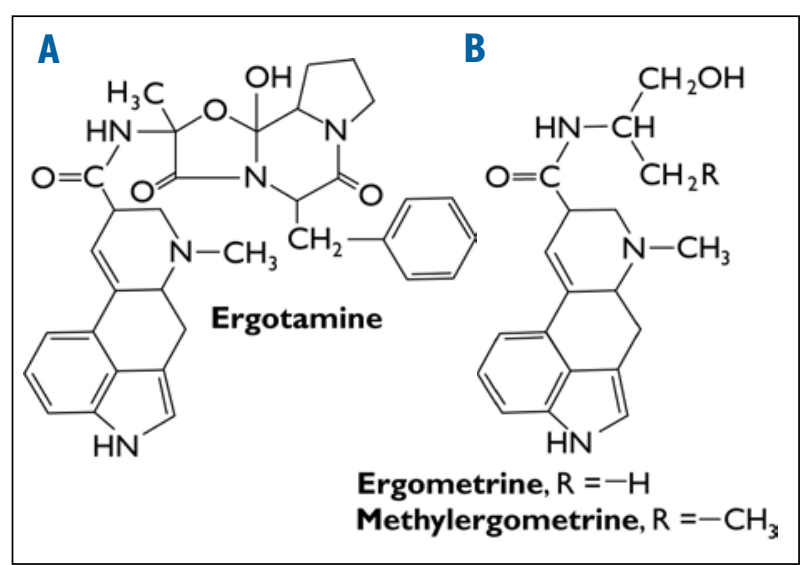

FIGURE 2 The chemical structure of $(A)$ ergotamine and (B) ergometrine. Note the amine side chain in ergometrine, responsible for hydrogen bonding with water molecules to produce its increased solubility.

became available in reasonable quantities it was shown to be more effective than ergotoxine. It then became a compound searching for a therapeutic outlet.

The first opportunity arose in 1926, when Hans Maier suggested that ergotamine might be useful in vascular headaches of the migraine type. It was tried immediately with great success.' In 1938 the empirical use of ergotamine in migraine with aura was given a strong theoretical basis by John Graham and Harold Wolff who demonstrated that the effect of ergotamine in reducing the headache in migraine closely paralleled the fall in pulse amplitude in the extracranial arteries. ${ }^{910}$ The vasoconstrictor effect on the arteries has been shown by more recent work to be explained by a partial agonist effect on serotoninergic and $\alpha$-adrenoceptors in the vessels." Other actions of ergotamine include the contraction of the uterus and the stimulation of vomiting by acting on chemoreceptors in the medulla oblongata.

Initially ergotamine was found to be safe in younger subjects but when its use was extended to older patients, dangerous side effects appeared. These worrying complications occurred particularly in patients with arterial disease and included a prolonged rise in blood pressure and/or constriction of the coronary arteries which could result in angina pectoris and/or myocardial infarction.

One property of ergotamine puzzled the early investigators. Although the alkaloid is cleared rapidly from the circulation with an elimination half-life of about two hours, the vasoconstrictor effect, principally on the arteries and arterioles, could last as long as $\mathbf{4 8}$ hours, so that in the German literature ergotamine became known as a 'chemical ligature or tourniquet'. Eventually this incongruity was solved by Peer Tfelt-Hansen and Lennart Paalzow in 1985 when they demonstrated that the bond between ergotamine and the serotonin receptor was extremely strong and stable. In fact, the affinity was 100 times that of serotonin (5-hydroxytryptamine [5-HT]), the endogenous 
ligand. ${ }^{12,13}$ This effectively irreversible binding of ergotamine to the $5-\mathrm{HT}$ receptor may go a long way towards explaining the damage to blood vessels that can occur, and the failure of nitrovasodilator agents such as sodium nitropresside to reverse the pathological vasoconstriction.

For severe migraine ergotamine was much more effective than the standard analgesics of the time. Only with the arrival of the non-steroidal anti-inflammatory agent ibuprofen in the 1960s did ergotamine have a serious rival.

What is the place of ergotamine today? It probably should be abandoned as two safer therapeutic groups are now available: the non-steroidal anti-inflammatory drugs for moderate attacks of migraine and the triptans for severe bouts. ${ }^{14}$ The latter group of drugs, for example sumatriptan, act as specific serotonin agonists. Nevertheless, we should remember ergotamine as the first alkaloid of ergot to be isolated. It deserves an honoured place in the history of pharmacology and therapeutics.

\section{Toxicity of ergotamine}

A number of patient groups have been shown to be particularly susceptible to the toxic effects of ergotamine, including individuals with hypertension, vascular disease and hepatic and renal damage. " More recently, ergotamine has been found to produce fibrosis in the valves of the heart, the mediastinum and the peritoneum. Patients who are taking either $\beta$-adrenoceptor blocking drugs or the combined oral contraceptive are particularly liable to develop these serious effects.

Sometimes ergotamine can produce a life-threatening clinical condition. With the pure alkaloid the nervous system is often spared and vascular complications predominate. ${ }^{15}$ Prolonged and excessive vasoconstriction results in damage to the intimal layer of the blood vessel. As a consequence, platelets adhere to the vessel wall, a fibrin clot is formed and thrombosis occurs. Death of the non-perfused tissue often results. This sequence of events is reminiscent of the gangrenous ergotism caused by rye grass infected with the Claviceps purpurea. ${ }^{16}$ Once started, the process of gangrenous ergotism is usually irreversible and unresponsive to vasodilators (see above).

Profound vasoconstriction when produced by ergotamine usually occurs in two well-defined circumstances: iatrogenic or deliberate self-administration of a large amount of the alkaloid in an attempt to induce an abortion. ${ }^{15}$ The first situation still occurs occasionally, but the second has disappeared in the UK with the advent of legal abortion in 1967. In a patient known to the author, a cumulative overdose of ergotamine was administered over ten days in the treatment of migraine.Warning symptoms of ergotism, including vomiting, cold feet and hands, shooting pains and paraesthesiae in the limbs, were ignored. As a result, necrosis of the legs up to the knees occurred and, inevitably, bilateral below-knee amputation.

\section{Pregnancy and abortion}

Pregnancy and ergot are inextricably linked. In the first instance, attacks of migraine can become more severe and more prolonged in pregnancy. As a result many women have taken an accidental overdose of ergotamine with disastrous results. Historically, powdered ergot (pulvis ad partum) was widely and successfully used to accelerate labour. ${ }^{16}$ However, the powder was also used to induce abortion. When ergotamine became generally available in the 1930s, it was not surprising that women with an unwanted pregnancy should choose ergotamine in an attempt to procure an abortion. Unfortunately, the results were unpredictable. There were a number of factors responsible, such as vomiting and diarrhoea causing a loss of dose. Given the fact that ergotamine does not have as powerful an action as powdered ergot (or ergometrine, see below) in contracting the uterus, it was not unusual for this organ to fail to expel the fetus. Perversely, serious toxic effects on the brain and cardiovascular system could still occur. As small a dose as $30 \mu \mathrm{g}$ of ergotamine has been reported to be lethal.

\section{ERGOMETRINE}

From work in the United States in the early part of the nineteenth century ${ }^{16}$ it had been established that fresh powdered ergot produced a marked contraction of the uterus (oxytocic or ecbolic effect). When 'ergotoxine' and ergotamine were examined the effect on uterine contraction of these substances was not marked. Something was missing! Dale and his colleagues at the National Institute for Medical Research in north London called this factor Ergot-X.

In the early 1930s a young obstetrician named John Chassar Moir entered the field (Figure 3). At that time he was first assistant to Professor Browne at University College Hospital in London. Having become fired with the idea of a powerful ergot oxytocic agent, Moir went to discuss with Dale a proposal for a bioassay employing postpartum women as subjects. Dale was excited at this prospect.

Moir had designed a primitive apparatus for the bioassay of ergot preparations. ${ }^{17}$ This consisted of a rubber balloon which was placed in the uterus of a postpartum woman. The balloon was connected to a water manometer in an adjoining room. The excursions of pressure in the manometer were recorded on a kymograph by a cork floating on the water attached to a needle surmounted by a stylus. ${ }^{17}$

For his first experiments Moir tested 'ergotoxine', which was still thought to be a pure substance, and ergotamine, the Stoll alkaloid. They were given either by mouth or intravenously. Both preparations proved to be reliable oxytocics. However, the latent period before the uterus contracted was often as long as 20 minutes 


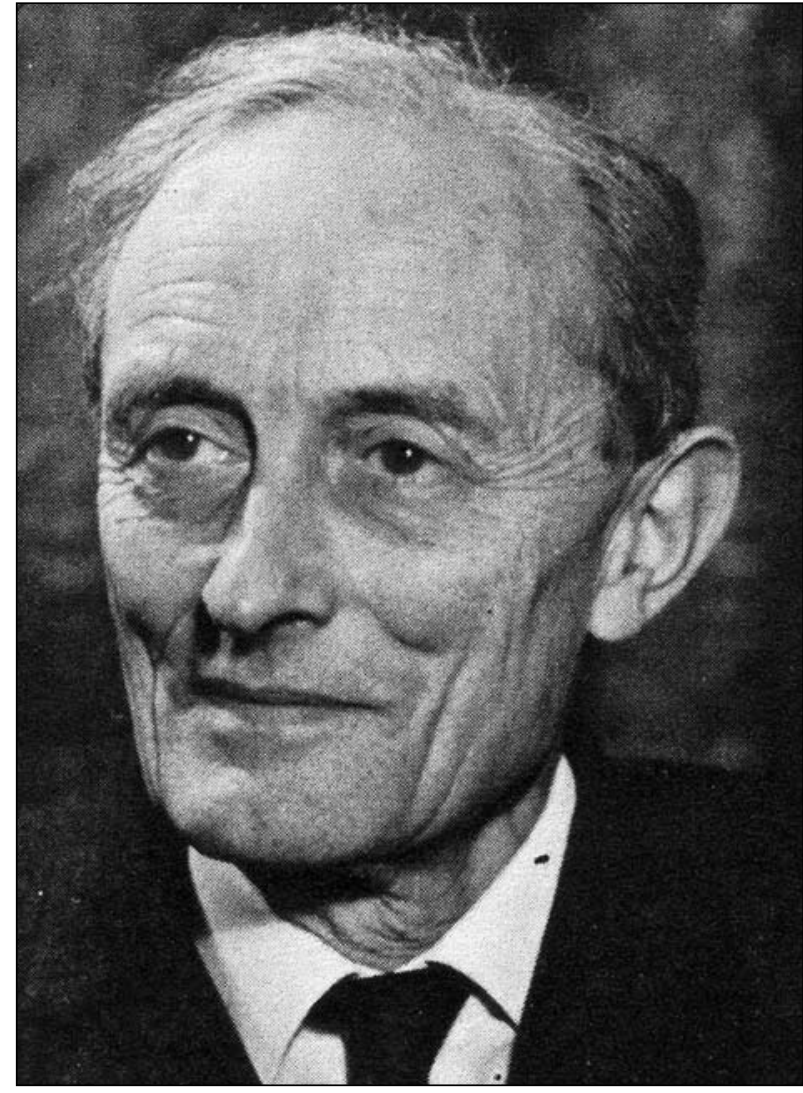

FIGURE 3 Professor John Chassar Moir, who studied the effects of ergot alkaloids on the uterus of postpartum women. (With kind permission of the Nuffield Department of Obstetrics and Gynaecology at the University of Oxford.)

(by mouth) and five minutes (intravenously). Moir was somewhat disappointed by these findings but decided to try the old-fashioned liquid extract of ergot. To his surprise, this proved to have an extremely powerful oxytocic effect: the kymograph needle shot up the manometer and Moir feared for his patient's safety. On stealing a glance into the patient's room, he found her unperturbed by the experiment, quietly eating lunch. ${ }^{18}$

The experiments were repeated a number of times and the liquid extract's potency was maintained. There was, in particular, no weakening of the response with repetitive dosing. ${ }^{7}$ Moir realised quickly that he had stumbled once again on the 'Stearns' effect'. The US investigator John Stearns had shown about a century earlier that ergot powder boiled in water 'will produce an effect on the uterus which will surprise you'. ${ }^{16}$

Moir showed these preliminary results to Dale who grasped immediately how important they were. He called in his colleague Harold Ward Dudley (Figure 4), a chemist, and asked him to abandon temporarily his work on acetylcholine and spermine and to direct all his energies to Ergot-X. Dudley started work in 1932 and his experiments would last until his premature death in 1935. Eventually he isolated, in 1935, a pure crystalline

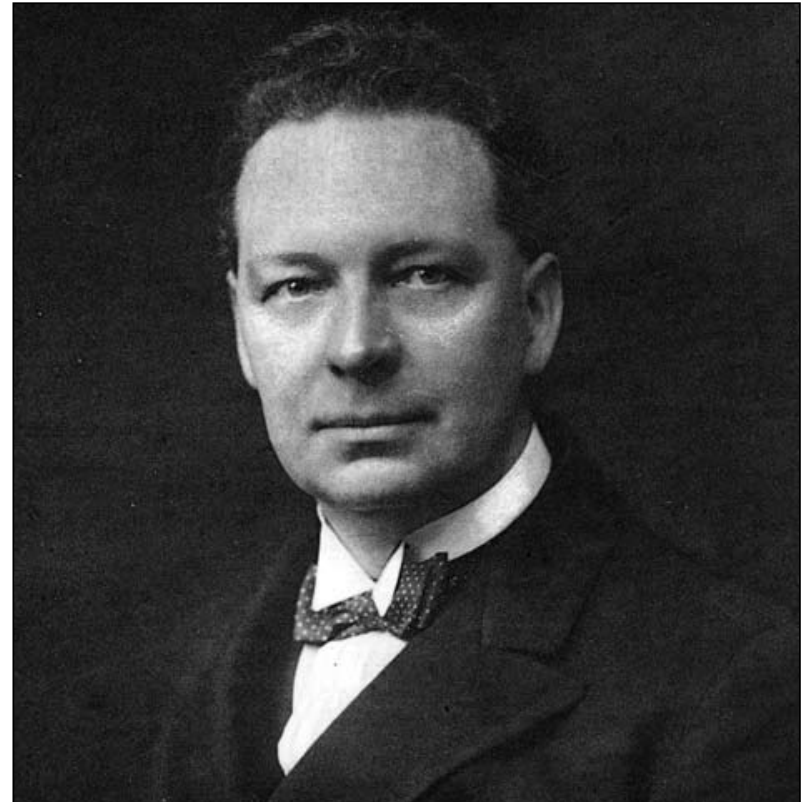

FIGURE 4 Harold Ward Dudley, who isolated and characterised the ergot alkaloid ergometrine. (Image from Obituary Notices of Fellows of the Royal Society 1935; I:595-606.)

substance which was a highly potent oxytocic with a rapid onset of action. Moir, Dudley and Dale decided to call it ergometrine. ${ }^{19}$

Dudley managed to submit a paper on ergometrine to the Royal Society in the summer of $1935,{ }^{20}$ but did not live to appreciate the recognition he (and Moir) would receive for this piece of work nor to realise how many lives would be saved by the use of ergometrine in serious postpartum haemorrhage. He sickened rapidly and died in hospital on 2 October, the very day on which his paper was published.

Dale was profoundly affected by the untimely death of Dudley. When, at the same time, several American groups also isolated and identified the principal oxytocic substance in ergot, they agreed to call it ergonovine. Dale was considerably irritated as he felt that all these groups had not given sufficient recognition to the work of Dudley and Moir. A prolonged dispute then occurred as to the primacy of the discoverer (or discoverers), which led to an impasse. In the end the British pharmacopoeia adopted ergometrine as the official name and the Americans countered with ergonovine. This confusion persists to the present day.

\section{Structure and actions}

The chemical structure of ergometrine is shown in Figure $2 B$. It represented the first of a new group of ergoline alkaloids to be recognised, the amines. The highly charged amino group (although substituted) accounts for ergometrine's increased solubility in aqueous extracts of the fungus. Ergometrine also shows enhanced water solubility because it readily forms hydrogen bonds with water molecules. ${ }^{20,21}$ 
Pure ergometrine is a powerful oxytocic agent. At low doses it increases the frequency (and amplitude) of contractions, whereas at high doses it also produces an increase in resting tone. The actions of ergometrine on the uterus were later shown to be mediated by $\alpha$-adrenoceptor activation and can be blocked by an $\alpha_{1}$-adrenoceptor blocker such as phentolamine. ${ }^{22}$ Moreover, when ergometrine is used intravenously the action on the uterus is immediate. This confers a definite advantage compared with ergotamine when the aim is to stop uterine haemorrhage immediately. This alkaloid can also constrict arteries, arterioles, veins and venules, but the effect is much less marked than with ergotamine. As a result, hypertension, angina, myocardial infarction and gangrene occur only rarely with ergometrine.

Ergometrine can, however, damage the fetus. Fetal death in utero has been described and therefore the alkaloid is usually given when the anterior shoulder is delivered. A curious fetal abnormality has also been documented as a result of ergometrine (Poland's syndrome). ${ }^{22}$ This consists of syndactyly and absence of the pectoralis major (or minor) muscles. Some women show an acute fall in plasma prolactin levels after the administration of intravenous ergometrine and this may interfere with the onset of lactation. ${ }^{23}$

At the present time ergometrine is one of the mainstays of obstetric therapeutics and is used widely throughout the developed world. It is extremely useful in postpartum and postabortal haemorrhage, in the third stage of labour and to accelerate involution of the uterus.

\section{REFERENCES}

I Dale HH. Les Prix Nobel in 1936. Stockholm: Nobel Foundation; 1937. p. 91-2.

2 Feldberg WS. Henry Hallett Dale, 1875-1968. Biogr Mem Fellows $R$ Soc 1970; 16:77-174. doi:10.1098/rsbm.1970.0006

3 Barger G, Dale HH. Ergotoxine and some other constituents of ergot. Biochem J 1907; 2:240-99.

4 Barger G. Ergot and ergotism. London: Gurney and Jackson; 193I.

5 Harington CR, Barger G. Chemistry of thyroxine III: constitution and synthesis of thyroxine. Biochem J 1927; 21:169-74.

6 Stoll A, Hofmann A. Partialsynthese von Alkaloiden vom Typus des Ergobasins. Helv Chim Acta 1943; 26:944-65. doi:10.1002/ hlca. 19430260326

7 Stoll A. Zur Kenntnis der Mutterkornalkaloide. Verh Schweiz Naturf Ges 1918; 101:190-I.

8 Stoll A, Hofmann A, Petrzilka T. Die Konstitution der Mutterkornalkaloide. Struktur des Peptidteils. III. Helv Chim Acta 1951; 34:I544-76. doi: 10.1002/hlca.19510340539

9 Silberstein SD, Lipton RB, Dalessio DJ, editors. Wolff's headache and other head pain. 7th ed. New York: Oxford University Press; 200I. p. I2I-237.

10 Graham JR,Wolff HG. Mechanisms of migraine headache and action of ergotamine tartrate. Arch Neurol Psychiatr 1938; 39:737-63.

II Dollery CT, editor. Ergotamine. In: Therapeutic drugs. Vol. I. Edinburgh: Churchill Livingstone; 1991. E42-E45.

I2 Müller-Schweinitzer E, Weidmann H. Regional differences in the responsiveness of isolated arteries from cattle, dog and man. Agents Actions 1977; 7:383-9. doi:10.1007/BF01969572

\section{ERGOT RESEARCH IN THE I940S}

By the beginning of the Second World War ergotamine and ergometrine had become well-established standard drugs. The research scene in the UK had changed considerably: Dudley and Barger had died prematurely, in 1935 and 1940 respectively. ${ }^{21,24}$ Dale retired as director of the National Institute for Medical Research in the early 1940s and became the 'grand old man' of British pharmacology. He was showered with honours, including the Nobel Prize, a knighthood and the Order of Merit. Moir moved to Oxford in 1937 to become the first Nuffield Professor of Obstetrics and Gynaecology. He never worked on ergot again but made a second international reputation on techniques to repair vesicovaginal and other fistulae following traumatic labour.

Switzerland maintained its traditional neutrality during the war and medical research proceeded apace at Sandoz. Stoll, Hofmann and others synthesised ergotamine in 194I and two years later established clearly that ergotoxine was not a pure substance. However, the major decision they took was to concentrate their attention on the action of defined compounds derived from ergot on the central nervous system; this would lead on to the discoveries of lysergic acid diethylamide and bromocriptine. ${ }^{23}$ Dale had begun a process in 1904 that would stimulate research in pharmacology for at least the next 70 years.

Acknowledgements I would like to thank the libraries of the Royal Society of London, the Royal College of Obstetricians of London and the Royal College of Physicians of Edinburgh. My thanks also to my secretary, Mrs May Gibb, and to Barlow Moor Books.

13 Tfelt-Hansen P, Paalzow L. Intramuscular ergotamine: plasma levels and dynamic activity. Clin Pharmacol Ther 1985; 37:29-35.

14 Joint Formulary Committee. British National Formulary. 53rd ed. London: British Medical Association and Royal Pharmaceutical Society of Great Britain; 2007. p. 237-9.

15 Berde B, Schild HO, editors. Ergot alkaloids and related compounds. Berlin, Heidelberg, New York: Springer; 1978.

16 Lee MR. The history of ergot of rye (Claviceps purpurea) I: from antiquity to 1900.J R Coll Physicians Edinb 2009; 39:179-84.

17 Moir JC, Dale HH. The action of ergot preparations on the puerperal uterus. $\mathrm{Br}$ Med J 1932; I:III9-22. doi:I0.II36/ bmj.I.3728.III9

18 Dunn PM. John Chassar Moir (1900-1977) and the discovery of ergometrine. Arch Dis Child Fetal Neonatal Ed 2002; 87:FI52-4. doi:I0.II36/fn.87.2.FI52

19 Dudley HW, Moir JC. The substance responsible for the traditional clinical effect of ergot. BMJ 1935; I:520-3. doi:I0.1 I36/ bmj.I.387I.520

20 Dudley HW. Ergometrine. Proc $R$ Soc Lond 1935; II8:478-84. doi:I0.1098/rspb.1935.0067

21 Dale HH. Dudley, Harold Ward. Obit Not Fell R Soc 1935; 1:595-606.

22 Dollery CT, editor. Ergometrine. In: Therapeutic drugs. Vol. I. Edinburgh: Churchill Livingstone; 199I. E38-E4I.

23 Lee MR. The history of ergot of rye (Claviceps purpurea) III: 1940-1980.J R Coll Physicians Edinb 2010; in press.

24 Dale HH. Barger, George. Obit Not Fell R Soc 194I; 3: 63-85. 